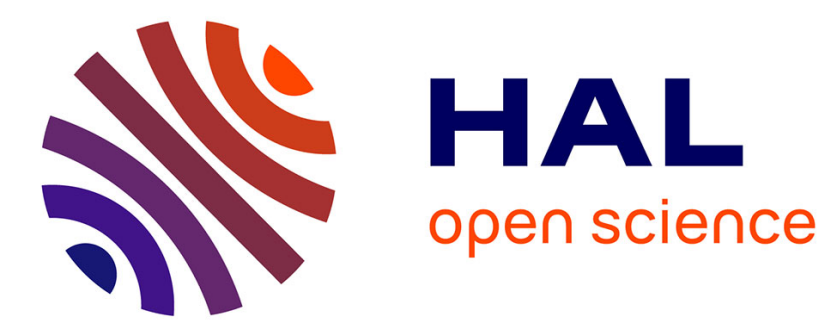

\title{
Potentially increased sawmill yield from hardwoods using X-ray computed tomography for knot detection
}

\author{
Stefan M. Stängle, Franka Brüchert, Antti Heikkila, Timo Usenius, Arto
}

Usenius, Udo H. Sauter

\section{- To cite this version:}

Stefan M. Stängle, Franka Brüchert, Antti Heikkila, Timo Usenius, Arto Usenius, et al.. Potentially increased sawmill yield from hardwoods using X-ray computed tomography for knot detection. Annals of Forest Science, 2015, 72 (1), pp.57-65. 10.1007/s13595-014-0385-1 . hal-01284151

\section{HAL Id: hal-01284151 \\ https://hal.science/hal-01284151}

Submitted on 7 Mar 2016

HAL is a multi-disciplinary open access archive for the deposit and dissemination of scientific research documents, whether they are published or not. The documents may come from teaching and research institutions in France or abroad, or from public or private research centers.
L'archive ouverte pluridisciplinaire HAL, est destinée au dépôt et à la diffusion de documents scientifiques de niveau recherche, publiés ou non, émanant des établissements d'enseignement et de recherche français ou étrangers, des laboratoires publics ou privés. 


\title{
Potentially increased sawmill yield from hardwoods using X-ray computed tomography for knot detection
}

\author{
Stefan M. Stängle • Franka Brüchert • Antti Heikkila • \\ Timo Usenius • Arto Usenius • Udo H. Sauter
}

Received: 15 November 2013 / Accepted: 29 April 2014 / Published online: 27 May 2014

(C) INRA and Springer-Verlag France 2014

\begin{abstract}
- Context One of the most important wood defects affecting the value yield from European beech (Fagus sylvatica [L.]) $\operatorname{logs}$ is knots that are visible on the sawn wood surface. The non-invasive technology of X-ray computed tomography (CT) can be used for the assessment of log internal features, especially the geometry and position of knots before primary breakdown to support the decision of value-optimised log rotation in sawmills.

- Aims The objective of this study was to test whether valueoptimised log rotation can be performed successfully by using the CT-derived knowledge of internal knottiness for the hardwood species beech.

- Methods Size parameters of 670 knots were measured and their position was marked in CT images from 33 logs. The 3Dreconstructed logs were virtually sawn in 12 different rotational angles using the software InnoSIM. This allowed visual grading of the simulated sawn wood and the calculation of product volume and value.
\end{abstract}

\section{Handling Editor: Barry Alan Gardiner}

Contribution of the co-authors Stängle: supervising the CT image analysis, running the data analysis and writing the paper;

Brüchert: developing the study design, supervising the work, coordinating the research project and revising the manuscript;

Heikkila: performing the sawing simulations and analysing data;

Usenius, T.: performing the sawing simulations;

Usenius, A.: supervising the sawing simulation, revising the manuscript; Sauter: coordinating the research project, supervising the work, revising the manuscript;

S. M. Stängle $\cdot$ F. Brüchert $(\bowtie) \cdot U$. H. Sauter

Forest Research Institute Baden-Württemberg, Wonnhaldestr. 4,

79100 Freiburg, Germany

e-mail: franka.bruechert@forst.bwl.de

A. Heikkila $\cdot$ T. Usenius $\cdot$ A. Usenius

VTT Technical Research Centre of Finland, Espoo, Finland
- Results The results show that if optimal rotation was applied to each single log, both total volume as well as total product value yield could be improved by up to $24 \%$ compared with the average yield of all simulated rotational angles.

- Conclusion In this small-scale study, it is demonstrated that CT technology could be used to support the decision about optimal rotational angle of beech logs to maximise volume and value yield.

Keywords CT $\cdot$ Wood quality $\cdot$ Knot detection $\cdot$ Fagus sylvatica $\cdot$ Sawing optimisation $\cdot \log$ rotational angle

\section{Introduction}

Log internal features such as knots, cracks, pith and rot make wood an inhomogeneous material, the potential use of which is affected by the occurrence of such defects. The value of sawn hardwood in Germany is determined by grading according to surface appearance, which primarily means the visibility of knots on the wood surface. The value yield from logs is ultimately limited by the knots present in the logs, but within that limit the value yield can be influenced by sawmill decisions about how they are processed. Decisions on log positioning, sawing pattern, edging and trimming made in sawmills to improve the yield can be summarized as sawing optimisation. Detailed knowledge about internal knottiness can support these decisions to minimise the occurrence of knots on the sawn wood surface and to maximise value yield from a given log. High price differences between sawn wood of different quality grades could increase the value gain of sawmills from sawing optimisation substantially (Rinnhofer et al. 2003).

Decisions about positioning and sawing patterns in Central European hardwood sawmills are usually made based on expert knowledge with the assistance of electronic 
measurement devices. The most common equipment uses laser technology to assess the outer shape of logs and singledirectional X-ray scanners with fixed X-ray sources to obtain information on $\log$ internal properties. As different wood structures usually show differences in their density, X-ray technology can be used to distinguish areas of contrasting density and consequently, to detect log internal features that would reduce the value of sawn wood. Most industrial X-ray scanners work with one to four views from fixed X-ray sources, resulting from the equivalent number of measuring directions. Such commonly applied technologies for roundwood assessment cannot exactly determine the location and geometry of defects such as knots. Thus, decisions about positioning of logs and sawing pattern are largely based upon the outer shape of logs and mainly consider volume yield. However, the log rotational angle chosen for highest volume yield is often different to the one that would result in highest value yield (Steele et al. 1993; Lundahl and Grönlund 2010). So it can be assumed that in most hardwood sawmills further optimisation with respect to value yield could be obtained with more information about log internal properties.

It has already been shown in other studies that X-ray based scanning can be implemented in industrial environments and used to increase yield by obtaining better knowledge of log internal properties before primary breakdown sawing (e.g. Bhandarkar et al. 2002; Berglund et al. 2013). The optimisation potential increases with increasing precision of the information about log internal defects (Todoroki 2003). X-ray computed tomography (CT) uses a rotating X-ray source and produces cross-sectional images that can be used to generate three-dimensional (3D) reconstructions of the scanned object. The use of CT-scanning considerably reduces the amount of work for log internal feature detection and log reconstruction compared with destructive tests such as those carried out by Steele et al. (1994). The review paper by Wei et al. (2011) shows that CT has proven to be a technology that can be used to detect log internal features like pith, cracks, rot and knots in much higher resolution and precision than traditional two-dimensional (2D) radiography. The accuracy of Xray images depends on density contrasts between different structures in the wood, which are generally greater in softwoods than in hardwoods, such as European beech (Fagus sylvatica [L.]) (Trendelenburg and Mayer-Wegelin 1955). Defect detection in CT images is, therefore, easier in softwood than in hardwood species. In Europe the focus of research on the industrial use of CT for log scanning has been focused on softwoods (Lundahl and Grönlund 2010; Berglund et al. 2013). In the USA, CT scanners have also been used to develop applications for the hardwood industry (Steele et al. 1994; Chang and Gazo 2009; Gazo and Benes 2013).

There are promising approaches that suggest defects in different hardwood species can be detected in CT images automatically (Sarigul et al. 2003; Thawornwong et al.
2003; Bhandarkar et al. 2006) or at least manually (e.g. Colin et al. 2010). It has also been shown that knot size and position in European beech can be determined with CT technology with high accuracy (Stängle et al. 2014).

The objective of this study was to test whether valueoptimised log rotation can be performed successfully by using the CT-derived information about internal knot morphology for beech. The first step was to reconstruct three-dimensional models of CT-scanned beech logs that included information about the outer shape and internal knottiness. Next, the model outputs were fed into the InnoSIM cutting simulation software (Song and Usenius 2007), which was used to perform alternate rotational log positioning before virtually live sawing of the logs. Finally, the quality of the generated sawn wood was determined; volume and value of the product yield were calculated and compared with three different sawing strategies: the mean yield obtained from all 12 simulated rotational angles, a volume-maximised rotation, and a value-maximised rotation.

\section{Material and methods}

\subsection{Beech logs}

Nineteen European beech trees were felled in two stands in the region of Karlsruhe, South West Germany. The stands ages were 110 and 130 years and both stands consisted of a Scots pine (Pinus sylvestris [L.]) and European beech mix. Selected trees showed diameters at breast height between 25 and $49 \mathrm{~cm}$, with a mean of $36.2 \mathrm{~cm}$ and a standard deviation (SD) of $8.0 \mathrm{~cm}$. Trees were felled and cross-cut into three logs of $4.1 \mathrm{~m}$ of length each.

\subsection{CT-scanning}

All 57 logs were scanned with a 2008-built CT scanner CT.LOG $^{\circledR}$ (MiCROTEC srl, Italy) at the Forest Research Institute Baden-Württemberg (FVA) in Freiburg. The resolutions were 1.1 and $5 \mathrm{~mm}$ for axial and longitudinal directions, respectively. From the raw data, a three-dimensional data block was computed where the greyscale value of each voxel (3D pixel) represented the X-ray attenuation of the corresponding point in the log. The complete scan of a single log took approximately $45 \mathrm{~min}$.

\subsection{Image analysis}

The position of the pith plays a decisive role in the analysis of CT data, as the pith is the origin of every knot and the approximation of the geometrical centre of a log, except for logs showing extreme eccentricity. Thus, the first step of analysis was the detection of the pith. A modification of the 
algorithm described by Boukadida et al. (2012) was used to determine the pith position in proprietary software developed by FVA and MiCROTEC. After this first step, 33 logs were selected for further experiments as the other $26 \operatorname{logs}$ either showed problems with strong X-ray artefacts or did not allow accurate automated pith detection and, therefore, no exact knot measurements. The selected logs showed top diameters between 17.5 and $46 \mathrm{~cm}$, with a mean of $31.2 \mathrm{~cm}$ and a SD of $8.1 \mathrm{~cm}$. These $33 \operatorname{logs}$ were graded according to the quality grading standards DIN EN 1316-1:2013-01 for beech logs applied in Germany (DIN 2013) by visually evaluating the 3D-reconstructions of CT scans on a monitor. The grades A to $\mathrm{D}$ describe four grades of decreasing quality, for which grade A must not have any characteristics that reduce its quality. Seven logs were classified as "B", 15 as "C", and 11 as "D". None of the logs were graded as "A". Figure 1 shows 3Dreconstructions of one crooked low-quality log with many branches and one higher-quality log.

The CT images were visually examined on a monitor for irregularities in greyscale values, representing the knots. For every clearly visible knot, the following was recorded: the radial distance from the pith to the end of the sound part, to the end of the dead part and the height and width of the knot at every $20 \mathrm{~mm}$ step from the pith (Fig. 2). The position of the starting point for each knot was described by its $x, y, z$ coordinates in the reconstructed image of the log. The growth direction of the knots was described by the azimuth to an automatically set reference line (Stängle et al. 2014). For each knot, those measured parameters were stored as text-files to be fed later into the cutting simulation software. The number of knots that can be detected in CT images depends strongly on the resolution of the scan, as this determines the minimum size of visible features. Manual validation measurements on radial cuts showed that the total length of knots can be visually

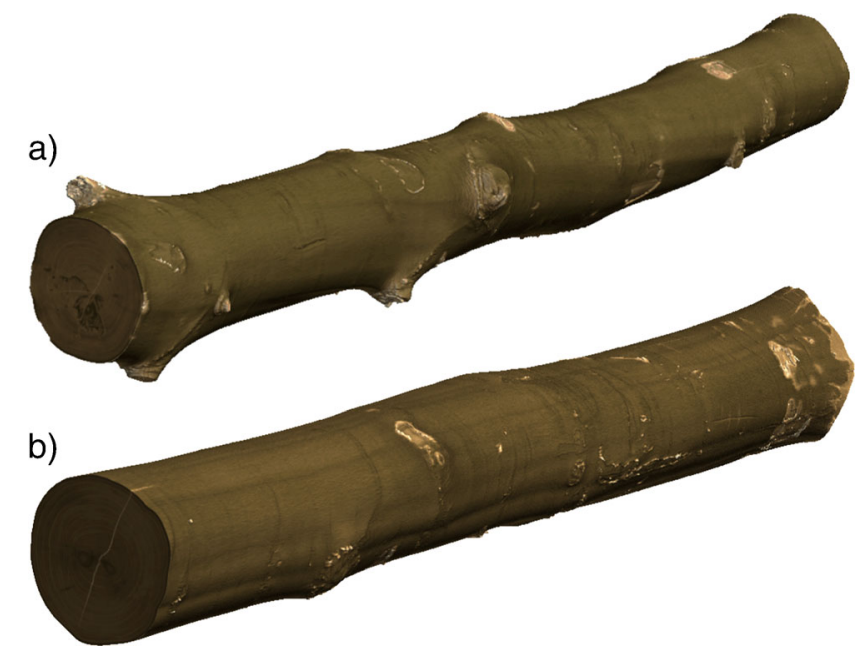

Fig. 1 3D reconstructions of computed tomography (CT) images of two example logs: a crooked log of quality grade "D" (log "B3") and b higher-quality log of grade "B" (log "D1")

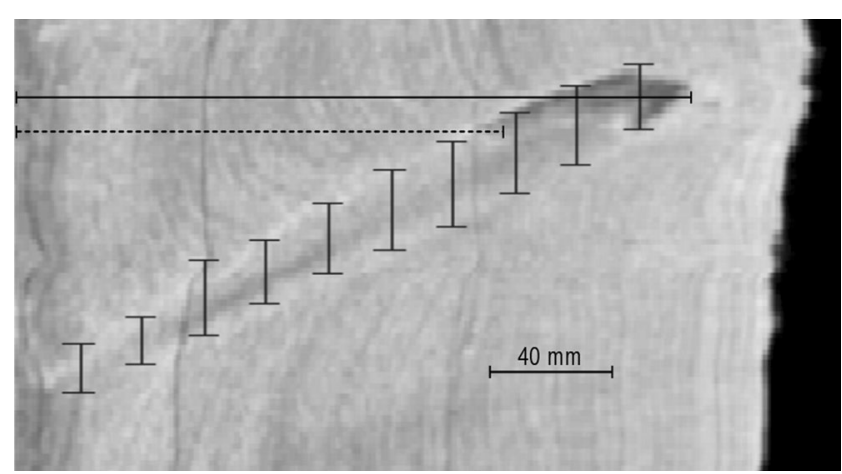

Fig. 2 Computed tomography (CT) image of a knot showing its maximum longitudinal extension. Vertical lines represent the diameter of the knot at each 20-mm step. The broken line represents the length of sound part of the knot and the solid line represents the total knot length including the dead part

determined on a monitor with high accuracy. As the knot length measurements could be performed accurately, it can be assumed that all knots, which are relevant for quality grading, were recognised (Stängle et al. 2014). In CT images of $33 \operatorname{logs}, 670$ knots were identified and measured.

\subsection{Cutting simulation}

The 33 logs were 3D-reconstructed with CT-derived information about the outer shape of the logs and the information about the position, geometry and direction of the knots in the $\log$ (Fig. 3). The reconstructed logs were virtually sawn using the cutting simulation software InnoSIM developed by VTT Technical Research Centre of Finland (Song and Usenius 2007). Twelve different log rotational angles deviating by $15^{\circ}$ from each other were applied to cut the logs into boards of even thickness of 32 and $38 \mathrm{~mm}$ for sideboards and centreboards, respectively. As boards were cut in the full log length, the number of boards and the board width was determined by the top log diameter. The saw kerf was $3.8 \mathrm{~mm}$ wide and no board trimming was performed. Live sawing was chosen for reasons of simplification and for comparability with other studies on sawing optimisation for hardwood, which also chose this sawing pattern (e.g. Steele et al. 1993; Chang et al. 2005; Chang and Gazo 2009). For each of the variants, the volume of edged sawn wood (boards), sawdust and wood chips was calculated. Edging of the boards was performed for maximum volume yield and did not consider value optimisation. Each virtual board was graded automatically according to an abridged version of the DIN standard EN 975-1:2011-08 (DIN 2011) by assessing its surface appearance. The only criterion from this standard taken into account in this study was knots (Table 1). First, for each side of each board, the running meter of lowest quality was determined and graded. The board was then graded as the better broadside of the board ("worst-case grading"). Boards with least defects were classified as grade 1, which corresponds to the DIN 
Fig. 3 Cutting simulation with InnoSIM: 3D saw log model that includes information on log shape and its knots (upper left); pseudocolour computed tomography (CT) reconstruction of a $\log$ and the chosen sawing pattern (upper right); a board that has been graded automatically according to its appearance (bottom)
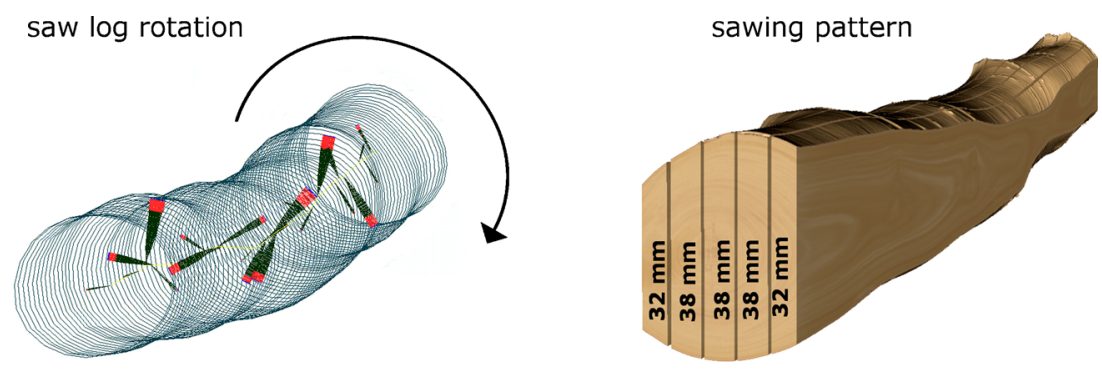

board grading and volume calculation

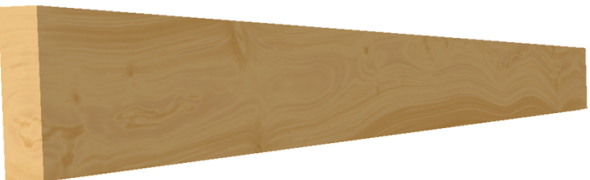

standard quality grade "F-F-1" (DIN 2011). Boards that showed more or severe defects were classified as grade 2 to grade 4 .

\subsection{Data analysis}

Data were analysed and plotted with the software $\mathrm{R}$ version 3.0.1 (R Development Core Team 2013) and Microsoft Excel (Microsoft Corp., Redmond, WA, USA 2010). Statistical tests were performed with SPSS Statistics for Windows version 21.0 (IBM Corp., Armonk, NY, USA 2012). Means are arithmetic means. For each log, the sawn wood volume and total product value yield from each of the 12 rotational angles was modelled. Two different strategies for optimised log rotation were compared: for maximum sawn wood volume ("max volume") and for maximum total product value ("max value"). To calculate the gain that could be obtained by selecting one of those improved rotational angles, a control value had to be set that best reflects the volume and value yield that would be obtained in a typical sawmill. To get such a control value, other studies perform mill cuts (e.g. Thawornwong et al. 2003; Chang and Gazo 2009; Lin and Wang 2012 ). One can argue, however, that a decision made by one sawyer in one selected mill is not necessarily representative for the average yield in an average sawmill. Standard sawing procedures could also be used as control rotational angles. Steele et al. (1994) used live sawing and grade sawing for hardwoods as control, Berglund et al. (2013) and Lundahl and Grönlund (2010) used the "hornsdown-position" as control for softwoods. However, for European beech there is no such procedure that would be applicable as a representative standard sawing procedure for most German sawmills. We decided, therefore, to compare the two strategies of optimised log rotation with each other and with the mean yield obtained from all 12 simulated rotational angles, which will be referred to as "average yield".

The difference between average yield and optimised yield will be referred to as improvement potential. As suggested by Steele et al. (1994), this improvement potential was calculated on a perlog basis, to better reflect the influence of the optimisation on the yield improvement than a mean for all logs would do. The improvement potential of the three log quality grades was compared with each other with a non-parametric Kruskal-Wallis test.

For sawn wood of the four quality grades and for the byproducts, current market prices were obtained from a local expert in spring 2012 (personal communication F. Sauter 2012). Additionally, to represent possible market fluctuations, pricing was varied in the simulations, assuming lower and higher price differences (Table 2). For each log, sawing simulation resulted in volume yield for each of the 12 rotational angles and product value yield for the respective angles and

Table 1 Criteria used for appearance grading of virtually sawn wood in accordance to the standard DIN EN 975-1:2011-08 (DIN 2011)

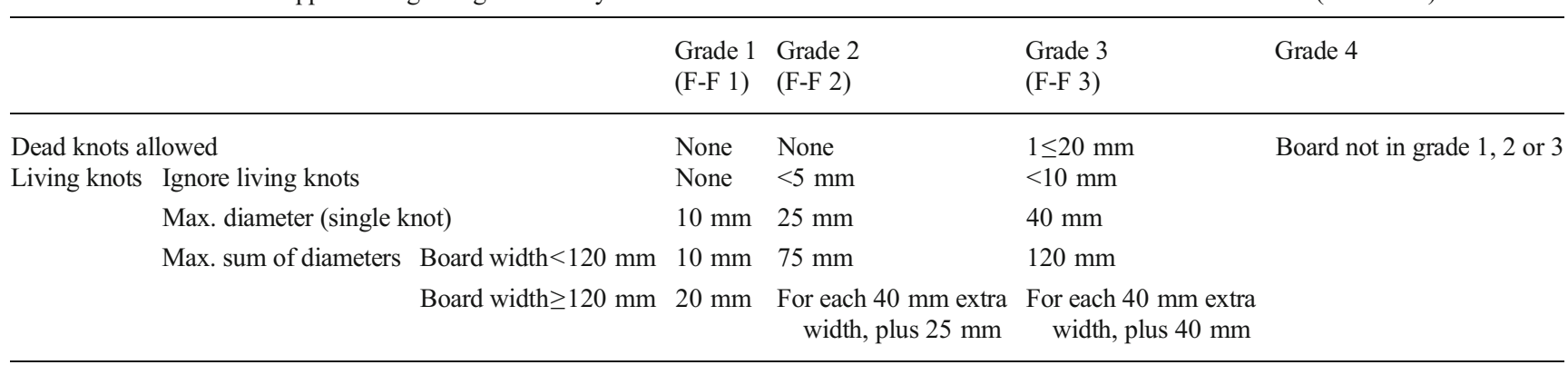


Table 2 Prices for different beech assortments used for calculations in the sawing simulation. Values for normal price differences obtained from F. Sauter (personal communication, 2012)

\begin{tabular}{llll}
\hline & \multicolumn{2}{l}{ Price $\left(€^{*} \mathrm{~m}^{-3}\right)$} & \\
\cline { 2 - 4 } Price differences & Normal & Low & High \\
\hline Grade 1 & 390 & 260 & 650 \\
Grade 2 & 290 & 210 & 450 \\
Grade 3 & 190 & 160 & 250 \\
Grade 4 & 130 & 130 & 130 \\
Chips & 40 & 40 & 40 \\
Sawdust & 30 & 30 & 30 \\
\hline
\end{tabular}

for the three pricings. Value was calculated as the sum of the value of sawn wood and all by-products to best reflect the practical optimisation potential.

The two optimised sawing strategies "max volume" and "max value" were compared with each other and with the average yield of all rotational angles by comparing the obtained sawn wood volume $\left(\mathrm{m}^{3}\right)$ and the value yield per cubic metre roundwood $(€)$. Paired $t$ tests at a significance level of $p=0.05$ were performed for each of the comparisons. This was done for the whole set of $33 \operatorname{logs}$, as well as for the three log grades separately. For comparing the monetary value yield, this procedure was also performed for the three different pricings. The simulated difference between minimum and maximum yield (range) of a single log was used as a measure to express the influence of the rotational angle on the yield. For illustration purposes, volume and value yields from each of the 12 rotational angles for each log were expressed as percent of the respective arithmetic mean yield of each log. In order that gain or loss could be easily compared on the same scale, yields for each log were standardised by setting the mean yield for that $\log$ to $100 \%$.

\section{Results}

Changes made to the log rotational angle led to large differences in the volume and value of product yield calculated by the sawing simulations. Results reveal that there is a conflict between volume and value maximisation: the respective rotational angle for these two strategies differed for 22 of $33 \mathrm{logs}$. In the example log "B3" (Fig. 4a), the highest volume yield could be obtained at a cutting angle of $150^{\circ}$; the value achievable at $105^{\circ}$ was $9 \%$ higher despite yielding only $82 \%$ of the maximum volume. Log "D1" (Fig. 4b) shows a more uniform relative volume and value distribution in the different rotational angles. The absolute differences are higher than for log "B3" because "D1" yields about six times as much volume and four times as much value.
The strongest influence of the rotational angle on sawn wood volume yield can be observed by a range of 265.2 percentage points for log "E3", whereas log "D1" with a range of 15.3 percentage points shows the lowest influence (Fig. 5). The total sawn wood volume of all 33 logs could be increased by $24 \%$ by selecting the optimal rotational angle compared with average yield. The "max value" strategy resulted in less volume, but boards of higher quality than the "max volume" strategy (Fig. 6). The recovery rates, the amount of the logs that could be converted to sawn wood, were $29 \%$ on average and 34 and $36 \%$ for the optimising strategies "max value", and "max volume", respectively.

Total product values show similar patterns as the yielded volume, though smaller ranges. The influence of the pricing on the value range can be seen in Fig. 7. Higher price differences led, in general, to larger ranges. For normal pricing, the range for the most uniform log is about 9.6 percentage points, whereas other logs vary up to 77.0 percentage points. Most of the logs that show high variation in volume yield also show high variation in value yield (e.g. "N2", "E3" and "H3" in Figs. 5 and 7). Nevertheless, some logs show a high value variation despite low volume variation (e.g. "H1" and "P2" in Figs. 5 and 7).

Without optimising the rotational angle, the mean achievable value per cubic metre roundwood is $93.40 €(\mathrm{SD} 22.22 €)$ for normal pricing. Optimised rotational orientation leads to 103.12 $€($ SD $22.33 €$ ) and $110.44 €($ SD $21.34 €$ ) for the strategies "max volume" and "max value", respectively (Fig. 8a). Value differences between the three simulations are significant $(p<0.05)$ for all three pricings when tested with paired $t$ tests.

By applying the "max value" strategy the value yield was 13,17 , and $24 \%$ higher than the average yield for the log grades $\mathrm{B}, \mathrm{C}$, and $\mathrm{D}$, respectively. The improvement potentials of the logs are significantly different between the three $\log$ grades $(p=0.044)$, when tested with a Kruskal-Wallis test. The mean improvement potential of the "max value" strategy compared to the "max volume" strategy is 7,5 , and $10 \%$ for B, C, and D logs, respectively (Fig. 8a). Here, no significant difference $(p=0.605)$ of the improvement potential could be found between the log grades. The range of value gains for different pricings (normal, high, low) are given in Fig. 8.

An increase of the rotational step size from 15 to $30^{\circ}$ reduces the value improvement potential by $1.9,2.7$, and 2.7 percentage points for the $\log$ grades $\mathrm{B}, \mathrm{C}$, and $\mathrm{D}$, respectively (Table 3). Paired $t$ tests showed that this reduction is significant $(p<0.05)$ for each of the log grades.

\section{Discussion}

Studies applying optimised log rotation for yield improvement showed that CT is a useful technology for sawmill optimisation (Chang and Gazo 2009; Lundahl and Grönlund 2010; Berglund et al. 2013). Simulated live sawing of 3D-reconstructed beech 
a) $\log B 3$

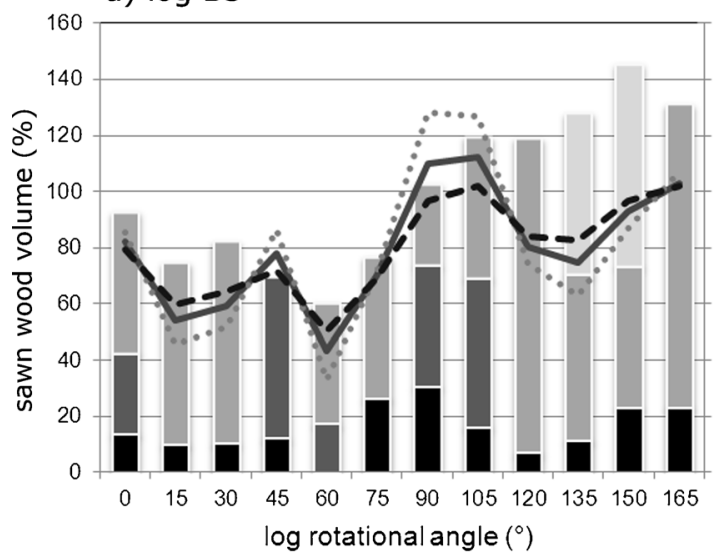

b) $\log D 1$

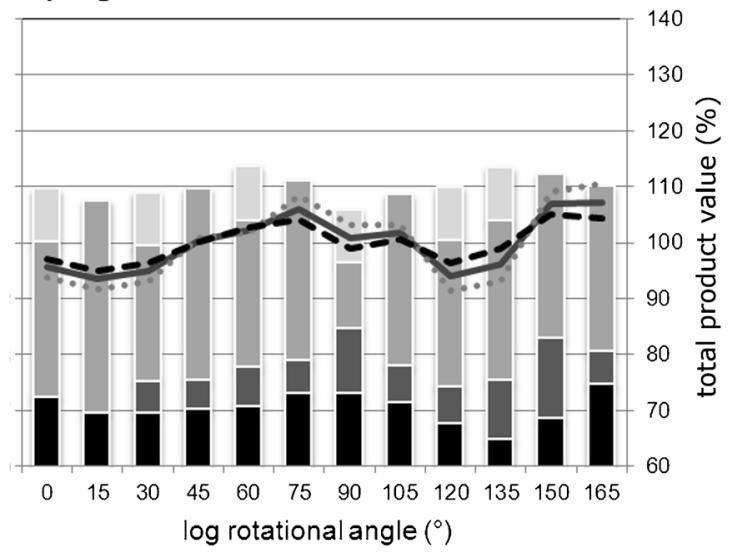

volume

grade 4

grade 3

grade 2

grade 1

value

normal pricing

..... high price differences

- - low price differences

Fig. 4 Board volume shown for the four quality grades (left axis) and the respective monetary value (right axis) yielded from 12 different rotational angles simulated for a the example logs "B3" (grade D) and b "D1" (grade B). Values of each log are standardised with the means set to $100 \%$

logs in this study confirmed that value-optimised log rotation is possible with CT-derived knowledge about log internal defects such as knots. We have shown that the improvement potential regarding the total product value is high, when compared with the arithmetic mean from 12 simulated rotational angles. Even if compared with a volume-optimised rotation, substantial value improvements are possible.

Volume and value optimisation potential per log was highest for logs of low quality. The value optimisation potential per log volume was significantly different for the three tested log quality grades, which corresponds to results by Chang and Gazo (2009). This stands in contrast to results of Steele et al. (1994), who described a similar optimisation potential for logs of different grades. Testing three different product pricings showed that the improvement potential is influenced by market prices, but that significant improvements are possible for a wide range of possible price development.

Limitations of our study are the small set of tested logs and the relatively high number of logs that could not be used for the sawing simulation due to problems with CT-scanning and defect detection. Depending on the dimensions and quality grades of tested logs, the improvement potential might differ significantly. High-grade logs containing very few internal defects were not tested in our study. Steele et al. (1994) suggest that altering the rotational angle might not influence the yield of such logs, as there will be few defects on the sawn wood surface no matter how the log is rotated. Logs of large diameter (butt end $>45 \mathrm{~cm}$ ) in our study often showed X-ray artefacts and could, therefore, sometimes not be used for the sawing simulation. For logs showing extreme eccentricity, crook or cracks close to the pith the algorithms used sometimes detected the pith incorrectly. Improved CT scanners of the same type, now have a slightly larger field of view and support a forwarding speed of up to $180 \mathrm{~m}^{*} \min ^{-1}$ (Gazo and Benes 2013); but only at a reduced spatial resolution. A limiting factor for further improvement is the development of stronger X-ray sources and corresponding detectors. For detailed defect detection in hardwood logs, there is clearly a limitation of market-

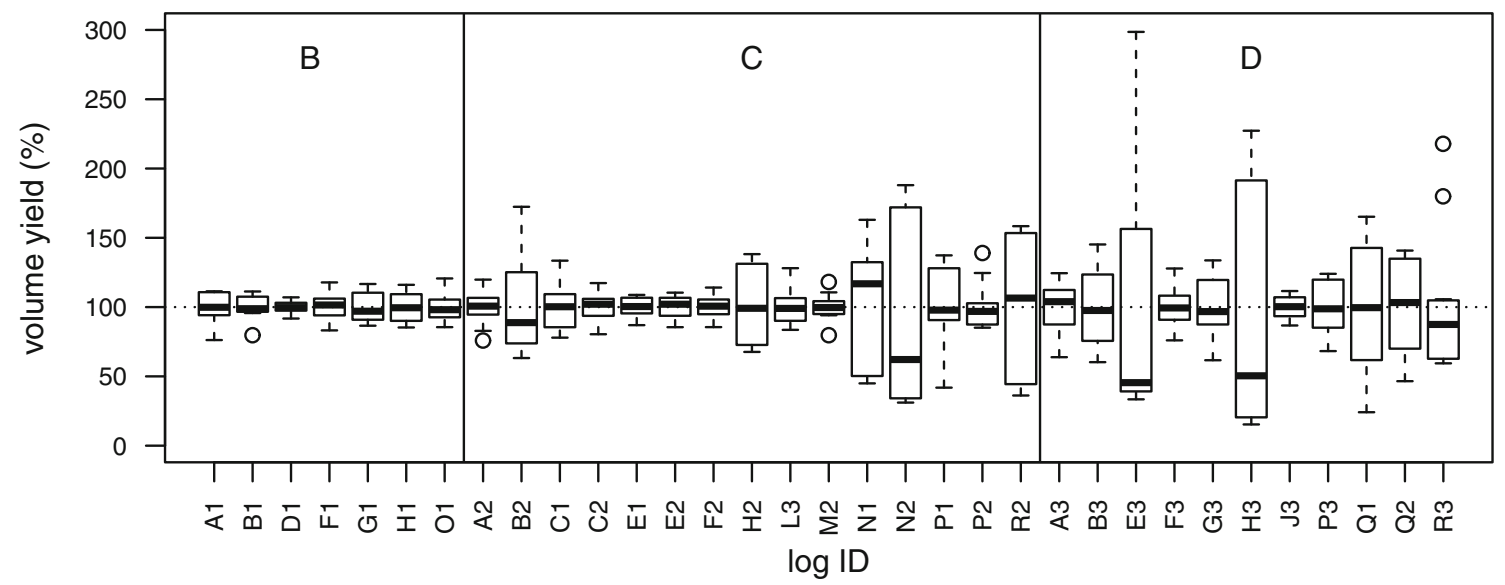

Fig. 5 Volume yield of edged sawn wood yielded from 12 different rotational angles as boxplots for 33 logs; grouped by log quality grade. Values are standardised with the mean volume yield set to $100 \%$ 


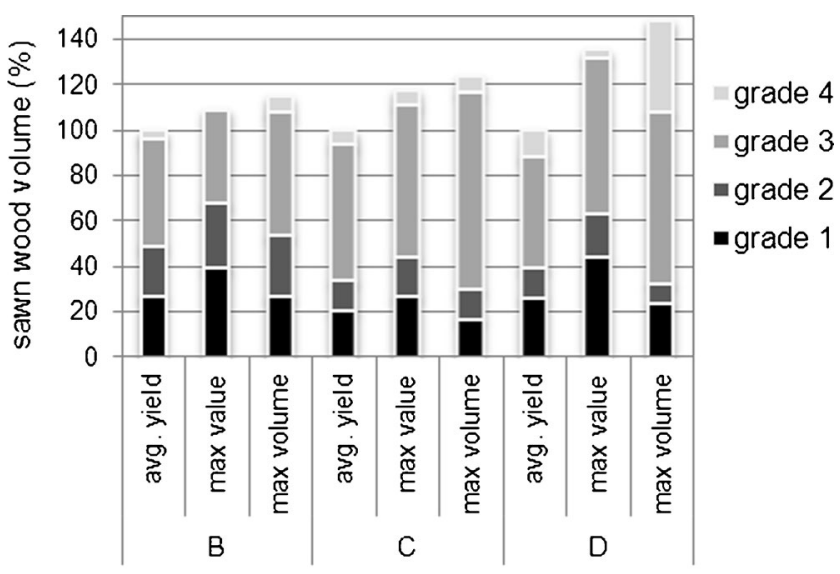

log quality grade and sawing strategy

Fig. 6 Volume yield of edged sawn wood for four different quality grades without optimisation (average yield from 12 rotational angles) and under application of two optimised sawing strategies "max value" and "max volume" grouped by log quality grade. Volume obtained is standardised with the values of the average yield set to $100 \%$ for each quality grade available industrial CT scanners on logs of small to medium diameter.

Knot measurements in CT images could be performed with high accuracy, the differentiation, however, between the dead and sound part of knots was difficult to perform due to lowdensity contrasts. The software used does not automatically recognise all kinds of wood defects and the technology does not yet work quickly enough for real-time application. CT scanners that are positioned in a sawline need to scan logs, process the data, and give best-option sawing instructions at production speed. In most hardwood sawmills, it takes approximately $1 \mathrm{~min}$ to saw a $\log$ of $4 \mathrm{~m}$ length when applying live sawing (Bhandarkar et al. 2002) and therefore data processing needs to be performed within the same time so as not to slow down the production process.

The log rotational angle was the only modified log positioning parameter in this study. Further optimisation could be achieved by lateral translation, skewing of the log and the initial

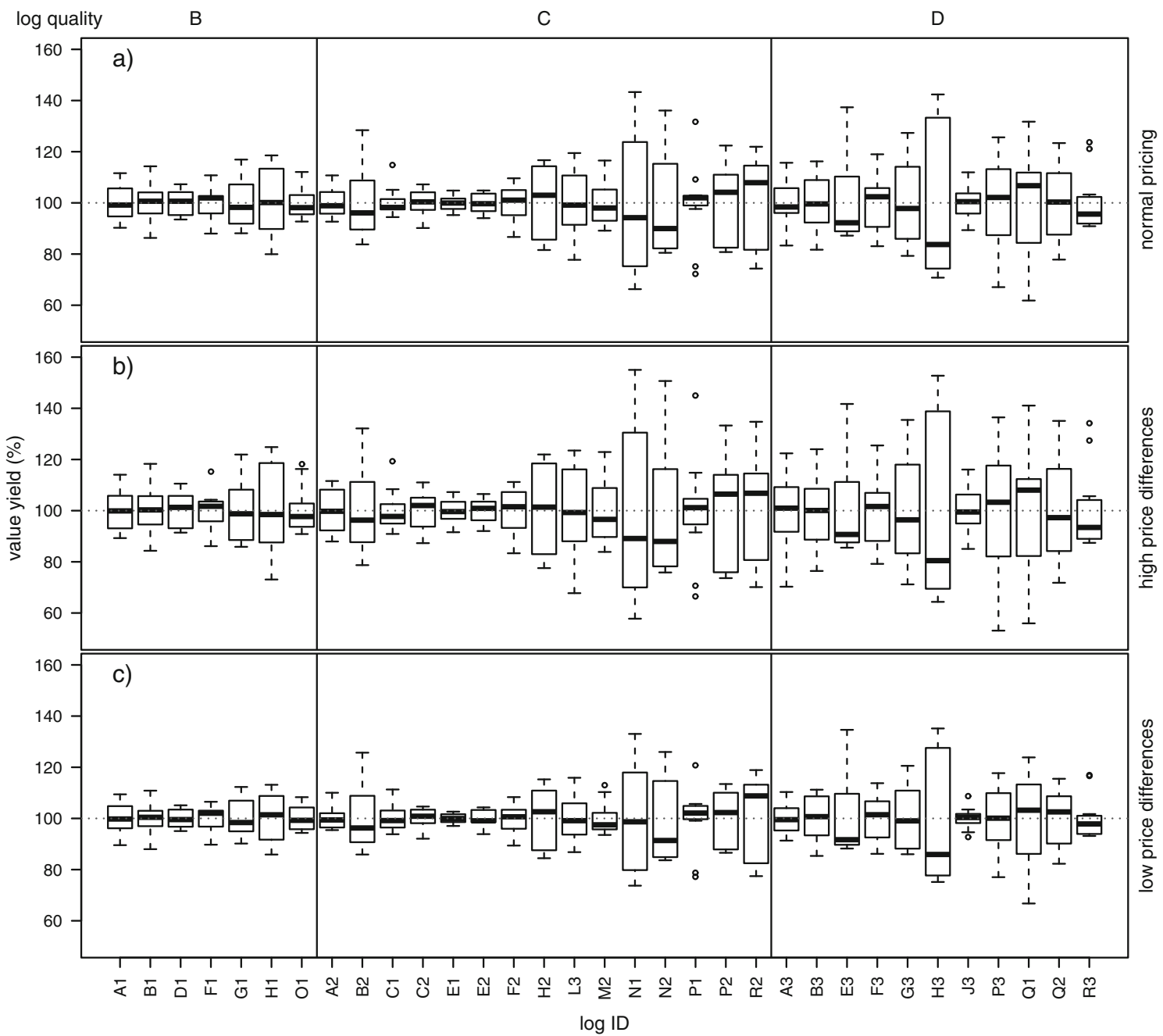

Fig. 7 Standardised total product value yield in 12 different rotational angles for 33 logs as boxplots; grouped by log quality grade. Values are shown for three different product pricings "normal" (a), "high differ- ences" (b), and "low differences" (c). Values are standardised with the mean value of each $\log$ set to $100 \%$ 


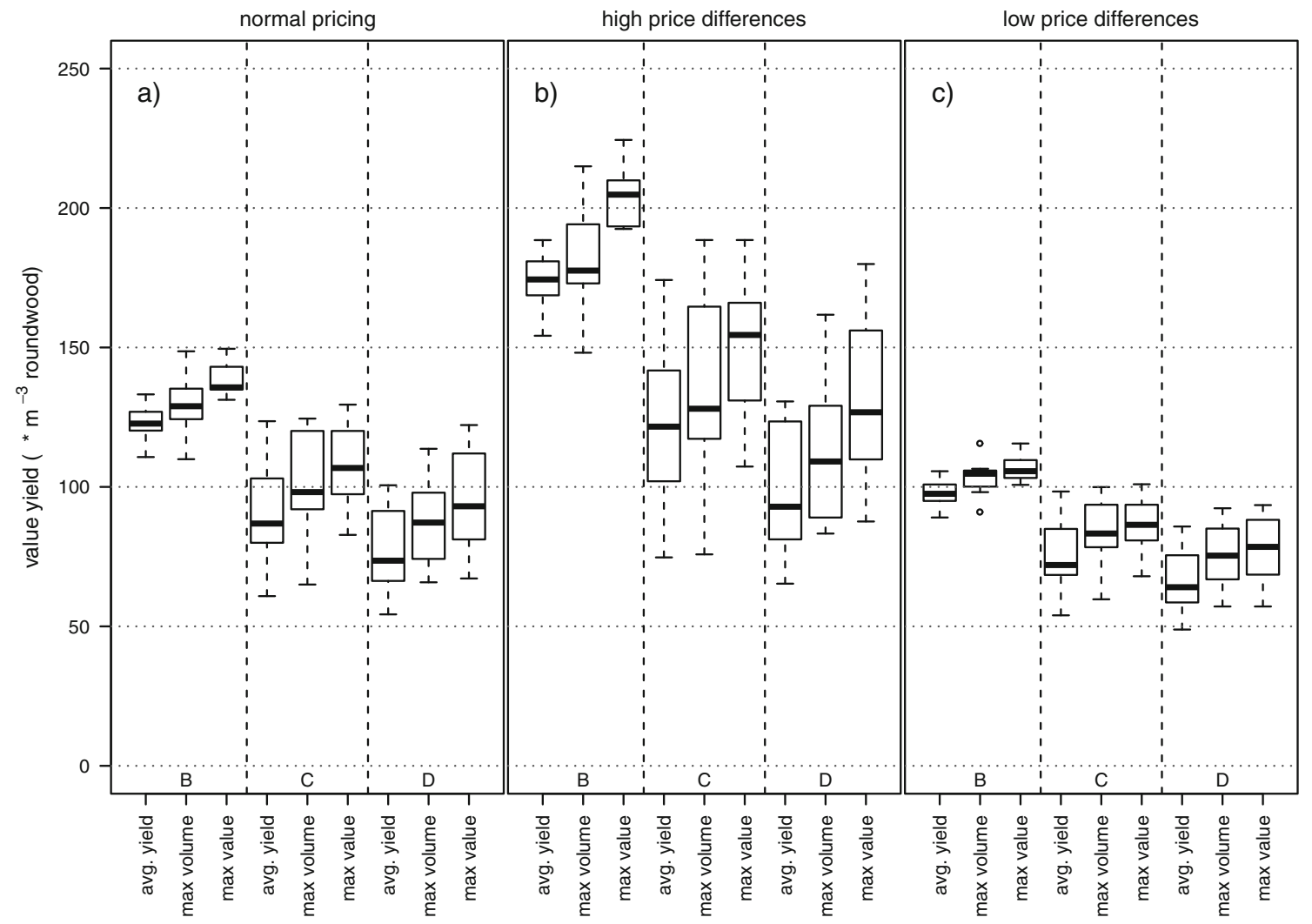

log qality grade and sawing strategy

Fig. 8 Total product value yield per cubic metre roundwood from without optimisation (average yield from 12 rotational angles) and from two sawing strategies with optimised log rotation: "max volume" and

opening face (Steele et al. 1993). Apart from choosing the best sawing position, board edging and trimming can also influence the grade and the value of sawn wood (Malcom 1964).

Twelve different rotational angles were chosen in this study due to practicability. Like our results, other studies have shown that increased rotational step size usually reduces the value improvement potential since optimal log rotations might be overlooked (Lundahl and Grönlund 2010; Berglund et al. 2013). Smaller rotational steps could possibly result in slightly higher improvement potentials (Berglund et al. 2013). The

Table 3 Value improvement potential (percentage increase between average yield and value-optimised yield) for a rotational step size of $15^{\circ}$ compared with one of $30^{\circ}$ for all three tested log grades

\begin{tabular}{lllll}
\hline & \multicolumn{3}{l}{ Rotational step size/number of simulated angles } \\
\cline { 2 - 3 } & $15^{\circ} / 12$ & & $30^{\circ} / 6$ \\
\cline { 2 - 3 } \cline { 5 - 5 } Grade & Mean (\%) & $\begin{array}{l}\text { Standard } \\
\text { deviation (\%) }\end{array}$ & Mean (\%) & $\begin{array}{l}\text { Standard } \\
\text { deviation (\%) }\end{array}$ \\
\hline B & 13.1 & 3.8 & 11.2 & 4.4 \\
C & 19.2 & 11.6 & 16.5 & 10.8 \\
D & 24.9 & 9.4 & 22.2 & 9.2 \\
\hline
\end{tabular}

"max value". Values are shown for three different product pricings: "normal" (a), "high price differences" (b), and "low price differences" (c) and are separated for the log grades "B", "C", and "D"

accuracy of the log forwarding and positioning system, however, is the limiting factor for any improvement. Small rotational errors can already reduce the improvement potential of rotational optimisation considerably as shown for the volume yield of pine (Wessels 2009) and value yield for spruce and pine (Berglund et al. 2013).

The presented results are based on a sawing simulation that produced even and straight boards. Optimisation results from live sawing patterns can be assumed to represent "conservative low-end estimate[s] of the potential gains" (Chang and Gazo 2009). Other sawing patterns or sawing techniques, such as curve sawing, could lead to an even higher optimisation potential. Further development of cutting simulation software might also include grading criteria other than knots. For beech, we automatically detected the pith; the detection of additional log internal features, such as cracks and rot are possible for other tree species (Laudon et al. 2012).

Industrial CT scanners are expensive investments for sawmills. The economic feasibility of CT in sawmills depends on the development of the CT technology and sawing simulation software, which includes speed, acquisition and maintenance costs, detection accuracy, and the kind of defects that can be detected. Additionally, the setup of the sawmill, characterised by quality and dimension 
of processed logs, wood species, processing speed, and product assortments, does influence yield improvement. Hodges et al. (1990) estimated that CT is likely profitable for medium to large size hardwood sawmills, but not for small sawmills as the cost of acquisition is too high. According to our results and current market prices of industrial CT scanners, this is still likely to be true. Few modern large size softwood sawmills in Central Europe already use CT technology to optimise their yield. However, it is expected that further algorithm development in the coming years will incite hardwood sawmills to increase investments in this technology.

To test CT technology as a tool for hardwood yield optimisation in practice, future studies could include different sawing patterns, as well as optimised edging and trimming. Simulated board quality should be validated with physical samples from sawing experiments; this is especially important to validate the accuracy of $\log$ rotation. Other types of defect could be included and other hardwood species tested. The real optimisation potential in sawmills could be examined by comparing the rotational angle that would be chosen by different sawing operators to the best-choice angle selected based on a CT-based sawing simulation.

It can be concluded that sawing optimisation of beech logs using a CT scanning system to detect log internal defects, followed by sawing simulation, can increase volume and value yield. It may therefore be a technology that supports better performance of hardwood sawmills in the future.

Acknowledgements The project was supported by the European Commission under the Food, Agriculture and Fisheries, and Biotechnology Theme of the 7th Framework Programme for Research and Technological Development, FP7 Grant Agreement No. 245136. We would like to thank all project partners involved in the FlexWood project. Furthermore, we thank Aikaterini Nakou for statistical advice. The suggestions from two anonymous reviewers and the associate editor were very much appreciated and helped improve the manuscript.

\section{References}

Berglund A, Broman O, Grönlund A, Fredriksson M (2013) Improved log rotation using information from a computed tomography scanner. Comput Electron Agric 90:152-158. doi:10.1016/j.compag.2012.09.012

Bhandarkar SM, Faust TD, Tang M (2002) Design and prototype development of a computer vision-based lumber production planning system. Image Vision Comput 20:167-189. doi:10.1016/S0262-8856(01)00087-7

Bhandarkar SM, Luo X, Daniels R, Tollner EW (2006) A novel featurebased tracking approach to the detection, localization, and 3-D reconstruction of internal defects in hardwood logs using computer tomography. Pattern Anal Appl 9:155-175. doi:10.1007/s10044-006-0035-9

Boukadida H, Longuetaud F, Colin F, Freyburger C, Constant T, Leban JM, Mothe F (2012) PithExtract: a robust algorithm for pith detection in computer tomography images of wood - application to 125 logs from 17 tree species. Comput Electron Agric 85:90-98. doi:10. 1016/j.compag.2012.03.012
Chang SJ, Gazo R (2009) Measuring the effect of internal log defect scanning on the value of lumber produced. For Prod J 59:5659

Chang SJ, Cooper C, Guddanti S (2005) Effects of the log's rotational orientation and the depth of the opening cut on the value of lumber produced in sawing hardwood logs. For Prod J 55:49-55

Colin F, Mothe F, Freyburger C, Morisset J, Leban JM, Fontaine F (2010) Tracking rameal traces in sessile oak trunks with X-ray computer tomography: biological bases, preliminary results and perspectives. Trees 24:953-967. doi:10.1007/s00468-010-0466-1

DIN (2011) DIN EN 975-1:2011-08: Sawn timber - Appearance grading of hardwoods - Part 1: Oak and beech; German version EN 975-1: $2009+$ AC:2010. Deutsches Institut für Normung e. V, Berlin

DIN (2013) DIN EN 1316-1:2013-01: Hardwood round timberQualitative classification-Part 1: Oak and beech; German version EN 1316-1:2012. Deutsches Institut für Normung e. V, Berlin

Gazo R, Benes B (2013) Computed tomography log scanning: an industrial application. In: Berti S, Achim A, Fioravanti M, Lihra T, Loewe Muñoz V, Marchal R, Wiedenbeck J, Zanuttini R (eds) ISCHP13 Proceedings, pp 140-147

Hodges DG, Anderson WC, McMillin CW (1990) The economic potential of CT scanners for hardwood sawmills. For Prod J 40:65-69

Laudon N, Baumgartner R, Brüchert F, Sauter UH (2012) Automatic Detection of Fungal Wood Decay in high-speed Computed Tomography Images. In: IUFRO-Division 5-Forest Products (ed) Proceedings of the 2012 IUFRO Conference All-Division 5 Forest Products, $\mathrm{p} 88$

Lin W, Wang J (2012) An integrated 3D log processing optimization system for hardwood sawmills in central Appalachia, USA. Comput Electron Agric 82:61-74. doi:10.1016/j.compag.2011.12.014

Lundahl CG, Grönlund A (2010) Increased yield in sawmills by applying alternate rotation and lateral positioning. For Prod J 60:331-338

Malcom F (1964) A simplified procedure for developing grade lumber from hardwood logs; Research Note FPL-098, Madison, Wis

R Development Core Team (2013) R: a language and environment for statistical computing. R Foundation for Statistical Computing, Vienna, Austria

Rinnhofer A, Petutschnigg A, Andreu J (2003) Internal log scanning for optimizing breakdown. Comput Electron Agric 41:7-21. doi:10. 1016/S0168-1699(03)00039-5

Sarigul E, Abbott A, Schmoldt DL (2003) Rule-driven defect detection in CT images of hardwood logs. Comput Electron Agric 41:101-119. doi:10.1016/S0168-1699(03)00046-2

Song T, Usenius A (2007) INNOSIM - a simulation model of wood conversion chain. In: van Acker J, Usenius A (eds) Modelling the wood chain: forestry-wood industry-wood product markets. Ghent University, Ghent

Stängle SM, Brüchert F, Kretschmer U, Spiecker H, Sauter UH (2014) Clear wood content in standing trees predicted from branch scar measurements with terrestrial LiDAR and verified with X-ray computed tomography. Can J For Res 44:145-153. doi:10.1139/cjfr-2013-0170

Steele P, Wagner F, Kumar L, Araman PA (1993) The value versus volume yield problem for live-sawn hardwood sawlogs. For Prod J 43:35-40

Steele P, Harless T, Wagner F, Kumar L, Taylor F (1994) Increased lumber value from optimum orientation of internal defects with respect to sawing pattern in hardwood sawlogs. For Prod J 44:69-72

Thawornwong S, Occeña LG, Schmoldt DL (2003) Lumber value differences from reduced CT spatial resolution and simulated log sawing. Comput Electron Agric 41:23-43. doi:10.1016/S0168-1699(03)00040-1

Todoroki C (2003) Accuracy considerations when optimally sawing pruned logs: internal defects and sawing precision. Nondestruct Test Eval 19:29-41. doi:10.1080/10589750310001613415

Trendelenburg R, Mayer-Wegelin H (1955) Das Holz als Rohstoff. Carl Hanser, Munich

Wei Q, Leblon B, La Rocque A (2011) On the use of X-ray computed tomography for determining wood properties: a review. Can J For Res 41:2120-2140. doi:10.1139/X11-111

Wessels CB (2009) Cant sawing log positioning optimization: a simulation study. For Prod J 59:17-22 